\title{
CBL Significance in Pathophysiology Teaching
}

\author{
Yanhua Zhang ${ }^{*}$, Haifeng Zhang2 ${ }^{*}$, Yue Li ${ }^{1}$, Xiaochun Peng ${ }^{3 \#}$ \\ ${ }^{1}$ Medical School of Yangtze University, Jingzhou, China \\ ${ }^{2}$ Department of Respiratory Medicine, Jingzhou Second People's Hospital, Jingzhou, China \\ ${ }^{3}$ Institute of Pathophysiology, Medical School of Yangtze University, Jingzhou, China \\ Email: "pxcwd789@sina.com
}

How to cite this paper: Zhang, Y.H., Zhang, H.F., Li, Y. and Peng, X.C. (2018) CBL Significance in Pathophysiology Teaching. Health, 10, 1673-1678.

https://doi.org/10.4236/health.2018.1012126

Received: November 6, 2018

Accepted: December 10, 2018

Published: December 13, 2018

Copyright $\odot 2018$ by authors and Scientific Research Publishing Inc. This work is licensed under the Creative Commons Attribution International License (CC BY 4.0).

http://creativecommons.org/licenses/by/4.0/

\begin{abstract}
Objective: To explore the importance of CBL in pathophysiology teaching. Methods: 218 undergraduate clinical medicine students in 2015 grade were divided into CBL group and control group, and each group had 109 students. The CBL group was taught by CBL, while the control group was taught by routine teaching mode. The teaching effects was evaluated by questionnaire survey and stage test. Results: The CBL group was superior to the control group in learning interest, logical thinking, knowledge system construction, comprehensive use of knowledge to solve problems. Conclusion: CBL teaching enhanced students' understanding of knowledge significantly, and also enhanced their clinical thinking and problem analysis ability.
\end{abstract}

\section{Keywords}

Pathophysiology, CBL, Clinical Thinking

\section{Introduction}

Pathophysiology is a bridge between basic medicine and clinical medicine [1] [2]. It needs to synthesize all kinds of knowledge about structure, function and metabolism in normal human body, so as to understand the changes in the body clearly when diseases occur. Whether the knowledge of pathophysiology is solid or not is related to the study of clinical courses and gives proper diagnosis and treatment for diseases after graduation. Compared with the traditional teaching mode, case-based learning (CBL) focuses on more attention to how to systematically teach students the knowledge of pathophysiology, and cultivate students' ability to analyze and solve problems [3]. This paper introduced the CBL method into daily teaching in order to improve students' curiosity and interest in learning, so as to inspire students' creative thinking.

*These authors contributed equally to this work. 


\section{Objects and Methods}

\subsection{Objects}

A total of 218 undergraduates of clinical medicine in 2015 grade who have studding pathophysiology were randomly divided into CBL group and control group, 109 students in each group. The CBL group was taught by CBL, while the control group was taught by routine teaching.

\subsection{Methods}

\subsubsection{Case Selected}

A suitable case has a direct impact on the final teaching effect. A successful case should have the following characteristics: 1) clear teaching objectives for the content; 2) based on clinical real cases; 3) typical cases, representative; 4) reasonable problem settings; 5 ) according to the teaching process, select cases with different difficulty. A case was presented below to illustrate the elements of case selection:

A patient, female, 36 years old, weighing $50 \mathrm{Kg}$, hospitalized due to burns. Burns covering $85 \%$ (III degree $60 \%$ ), and severe respiratory burns.

Admission spirit clear, but apathy, difficulty in breathing, blood pressure $75 / 55 \mathrm{mmHg}$, and hemoglobinuria. Laboratory tests: $\mathrm{Hb} 152 \mathrm{~g} / \mathrm{L}, \mathrm{RBC} 5.13 \times$ $10^{12} / \mathrm{L}, \mathrm{pH} 7.312, \mathrm{HCO}_{3}^{-} 15.1 \mathrm{mmol} / \mathrm{L}, \mathrm{PaCO}_{2} 55 \mathrm{mmHg}, \mathrm{K}^{+} 4.2 \mathrm{mmol} / \mathrm{L}, \mathrm{Na}^{+}$ $135 \mathrm{mmol} / \mathrm{L}, \mathrm{CL}^{-} 101 \mathrm{mmol} / \mathrm{L}$.

Immediate tracheotomy, oxygen, intravenous fluids and other emergency treatment. $24 \mathrm{~h}$ after injury total complement plasma $400 \mathrm{ml}$, dextran $500 \mathrm{ml}, 5 \%$ dextrose in water $1400 \mathrm{ml}, 20 \%$ mannitol $200 \mathrm{ml}, 10 \% \mathrm{KCL} 10 \mathrm{ml}$. Patients general condition, blood pressure 90/70, urine $1836 \mathrm{ml} / 24 \mathrm{~h}$, hb $119 \mathrm{~g} / \mathrm{L}, \mathrm{pH} 7.38$, $\mathrm{HCO}_{3}^{-} 23.4 \mathrm{mmol} / \mathrm{L}, \mathrm{PaCO}_{2} 41 \mathrm{mmHg}$.

Soon, patients with rapid shallow breathing, the lungs moist rales, $\mathrm{X}$ ray showed pulmonary edema. The next morning laboratory tests: $\mathrm{pH}$ 7.352, $\mathrm{HCO}_{3}^{-}$ $36.3 \mathrm{mmol} / \mathrm{L}, \mathrm{PaCO}_{2} 66 \mathrm{mmHg}, \mathrm{Na}^{+} 140 \mathrm{mmol} / \mathrm{L}, \mathrm{Cl}^{-} 107 \mathrm{mmol} / \mathrm{L}$. immediately artificial ventilation, that afternoon $\mathrm{pH} 7.542, \mathrm{HCO}_{3}^{-} 15.7 \mathrm{mmol} / \mathrm{L}, \mathrm{PaCO}_{2} 18.8$ $\mathrm{mmHg}$, adjusted ventilation, later more than 10 days in a stable condition.

28 days after admission, wound infection (Pseudomonas aeruginosa) occurred, sepsis, blood pressure drops to $70 / 50 \mathrm{mmHg}$, urine $40 \mathrm{ml} / \mathrm{day}$, $\mathrm{pH} 7.088$, $\mathrm{HCO}_{3}^{-} 9.8 \mathrm{mmol} / \mathrm{L}, \mathrm{PaCO}_{2} 33.4 \mathrm{mmHg}, \mathrm{K}^{+} 5.8 \mathrm{mmol} / \mathrm{L}, \mathrm{Na}^{+} 132 \mathrm{mmol} / \mathrm{L}, \mathrm{CL}^{-}$ $102 \mathrm{mmol} / \mathrm{L}$. Despite aggressive treatment, the disease is still no improvement, at the end the patient die because of toxic shock and pseudomonas aeruginosa sepsis.

This case was a summary of the previous four chapters of pathophysiology. We set the following four questions: 1) How many stages in this case? 2) What kind of water, electrolyte metabolism disorders and acid-base balance disorders may occur in this patient? 3) Give evidence; 4) What are the causes of these disorders?

First of all, the case was streamlined by experienced teachers on the basis of 
the original case, and the contents unrelated to the teaching objectives were removed as far as possible without affecting the case itself, leaving information closely related to water, electrolyte metabolism disorders and acid-base disorders. The aim is to get junior students with few cases into the role as soon as possible and to avoid complicated information interfering with students' thinking. In view of this case, the four questions were put forward from superficial to deep. Finally, the basic knowledge and theory were combined with clinical symptoms and signs, which not only deepened the students' understanding of pathophysiology, but also improved their ability to analyze cases. Simple cases like the ones mentioned above occur in almost every chapter. When students are familiar with the form of case discussion and enter the stage of pathophysiology study of each system, the author introduces more complex clinical cases such as those related to heart failure, increases interference information, and raises more in-depth questions, this all help to improve students' clinical logical thinking ability.

\subsubsection{Preparations before Class}

Before discussing cases in groups, teachers should first use one or two classes to introduce the basic idea of case analysis concisely and briefly, and tell students how to make full use of library, network and other resources to learn relevant knowledge in advance.

\subsubsection{Discuss in Class}

If case selection is reasonable and students are well prepared, classroom discussions will basically be a half success. So the teacher must do a good job of directing, before each group member speaks, the teacher should mobilize, affirm the preparation of students before class, again briefly introduce the case, but do not analyze the case. We should pay attention to control the rhythm and avoid "cold field" as far as possible. We can put forward corresponding questions according to different students' view points, and constantly revise the direction of students' discussion so as to avoid deviating from the teaching objectives. If there are fewer groups, you can make comments in sections after each group's closing remarks. The comments are mainly encouraged by affirmation. Don't be anxious to announce the answers to the questions that students have not answered correctly. Some heuristic questions should be put forward to guide the students.

\subsubsection{Summary}

Affirming the students' achievements, pointing out the shortcomings, emphasizing the correct thinking of case analysis, giving the corresponding reference answers for specific cases, further explaining with theoretical knowledge, deepening the students' understanding of the important and difficult points. The differences between the CBL group and the control group were investigated through questionnaires and phase tests.

\subsubsection{Statistical Analysis}

SPSS20.0 software is used for data processing, the measurement data were ex- 
pressed by t-test (mean + standard deviation) and the counting data by chi-square test (\%), $\mathrm{P}<0.05$ was accepted as indicating statistical significance.

\section{Results}

The students in the CBL group are well prepared before class, have active discussions, have a deep understanding of knowledge, have a well-organized statement, and have a strong ability to apply knowledge comprehensively when solving problems. Questionnaires include improving interest in learning, self-study ability, and logical thinking ability, innovative ability, understanding of knowledge, building knowledge system, comprehensively using knowledge to solve problems, improving literature retrieval ability, communicating and expressing ability, and improving teamwork ability. The positive response rates of the CBL group were $92 \%, 75 \%, 74 \%, 59 \%, 100 \%, 100 \%, 92 \%, 93 \%, 85 \%$ and $76 \%$ respectively, while those of the control group were $41 \%, 72 \%, 30 \%, 45 \%, 34 \%, 32 \%$, $58 \%, 85 \%, 62 \%$ and $65 \%$, respectively, CBL teaching can help students to increase learning interest, understand knowledge and build knowledge system well, also increased them logical thinking ability, solving problems ability, communicating and expressing ability, Table 1.

Stage test in which all questions from the first 4 chapters of pathophysiology fully reflected the students' ability to solve problems, and the total score was 100 points. The scores of the CBL group and the control group were $88.7 \pm 3.58$ and $78.5 \pm 3.25$, respectively. The paired t-test analysis showed that there was significant difference between the two groups $(\mathrm{P}<0.01)$, Table 2 .

Table 1. Ability between two groups.

\begin{tabular}{ccccc}
\hline & $\begin{array}{c}\text { Control group } \\
(\mathbf{N}=109)\end{array}$ & $\begin{array}{c}\text { CBL group } \\
(\mathbf{N}=109)\end{array}$ & $\chi^{2}$ & P \\
\hline Interest in learning & $41 \%$ & $92 \%$ & 60.056 & $<0.001$ \\
Self-study ability & $72 \%$ & $75 \%$ & 0.211 & 0.646 \\
Logical thinking ability & $30 \%$ & $74 \%$ & 40.618 & $<0.001$ \\
Innovative ability & $45 \%$ & $59 \%$ & 3.601 & 0.058 \\
Understanding of knowledge & $34 \%$ & $100 \%$ & 104.541 & $<0.001$ \\
Building knowledge system & $32 \%$ & $100 \%$ & 109.02 & $<0.001$ \\
Solve problems ability & $58 \%$ & $92 \%$ & 31.515 & $<0.001$ \\
Improving literature retrieval ability & $85 \%$ & $93 \%$ & 2.892 & 0.089 \\
Communicating and expressing ability & $62 \%$ & $85 \%$ & 14.682 & $<0.001$ \\
Improving teamwork ability & $65 \%$ & $76 \%$ & 2.676 & 0.102 \\
\hline
\end{tabular}

Table 2. Score between two teaching methods.

\begin{tabular}{cccc}
\hline & Score $(\mathbf{x} \pm \mathbf{s})$ & $\mathrm{T}$ & P \\
\hline Control group $(\mathrm{N}=109)$ & $78.5 \pm 3.25$ & & \\
CBL group $(\mathrm{N}=109)$ & $88.7 \pm 3.58$ & -22.024 & $<0.001$ \\
\hline
\end{tabular}




\section{Discussion}

1) $\mathrm{CBL}$ enhanced students' learning initiative. Psychologist Bruner believes that the best motivation for learning is that students have an intrinsic interest in what they have learned, interest is the source of motivation for learning, and good teaching methods can stimulate students' interest in learning [4]. For example, when it comes to hypoxia, the teacher will first mention the hypoxia caused by altitude hypoxia and gas poisoning and other medical records, linking the clinical manifestations, diagnosis and treatment with the theoretical knowledge of pathophysiology, so that students can find pleasure in learning [5]. The learning effect is recognized, thus enhancing their self-confidence in learning is very important.

2) CBL cultivated students' ability to integrate theory with practice. Students will not only link the theory of pathophysiology with clinical knowledge, but also integrate other basic and clinical disciplines such as physiology, diagnostics, surgery and so on. Imparting knowledge is the responsibility of teachers, but to teach students how to acquire knowledge is really the purpose of teachers [6]. The application of CBL is an important means to improve teaching quality, develop students 'intelligence and teach them learning methods. So, teachers need to constantly improve and innovate in the process of using heuristic teaching, so that medical students can maximize their ability through higher education.

\section{Conclusion}

In conclusion, the use of CBL in pathophysiology enhanced students' understanding of knowledge, and also improved their clinical thinking and problem analysis ability greatly.

\section{Acknowledgements}

The present study was supported by the Nature Science Foundation of Hubei Province (grant no. 2017CFB786), Hubei Province health and family planning scientific research project (grant no. WJ2016-Y-10), the College Students Innovative Entrepreneurial Training Program in Yangtze University (grant no. 2017056) and Hubei Ministry of education young talents Project (grant no. Q20161305).

\section{Conflicts of Interest}

None declared.

\section{References}

[1] Branney, J. and Priego-Hernández, J. (2018) A Mixed Methods Evaluation of Team-Based Learning for Applied Pathophysiology in Undergraduate Nursing Education. Nurse Education Today, 61, 127-133. https://doi.org/10.1016/j.nedt.2017.11.014

[2] Peng, X.C. and Ma, H.Y. (2017) Application of Problem Based Learning in Patho- 
physiology Teaching. Journal of Yangtze University, 14, 76-77.

[3] Aluisio, A.R., Daniel, P., Grock, A., et al. (2016) Case-Based Learning Outperformed Simulation Exercises in Disaster Preparedness Education among Nursing Trainees in India: A Randomized Controlled Trial. Prehospital and Disaster Medicine, 31, 516-523. https://doi.org/10.1017/S1049023X16000789

[4] Mabbe, E., Soenens, B., De Muynck, G.J., et al. (2018) The Impact of Feedback Valence and Communication Style on Intrinsic Motivation in middle Childhood: Experimental Evidence and Generalization across Individual Differences. Journal of Experimental Child Psychology, 170, 134-160. https://doi.org/10.1016/j.jecp.2018.01.008

[5] Peng, X.C., Ma, H.Y. and Lei, Y.W. (2014) Application of Logical Thinking in Pathophysiology Teaching. Basic Medical Education, 16, 342-344.

[6] Ofei-Dodoo, S., Goerl, K. and Moser, S. (2018) Exploring the Impact of Group Size on Medical Students' Perception of Learning and Professional Development during Clinical Rotations. Kansas Journal of Medicine, 11, 70-75. 